\title{
IS THE CHILD-TO-CHILD APPROACH USEFUL IN IMPROVING UPTAKE OF EYE CARE SERVICES IN DIFFICULT-TO-REACH RURAL COMMUNITIES? EXPERIENCE FROM SOUTHWEST NIGERIA
}

\author{
O.O. Ayorinde ${ }^{1}$, G.V.S. Murthy ${ }^{2}$ and O.O. Akinyemi ${ }^{3}$
}

1. Department of Ophthalmology, University College Hospital, Ibadan, Nigeria

2. International Centre for Eye Health, London School of Hygiene and Tropical Medicine, London

3. Department of Health Policy and Management, College of Medicine, University of Ibadan, Ibadan, Nigeria

\section{Correspondence:}

Dr. O.O. Akinyemi

Dept. of Health Policy and Management, College of Medicine,

University of Ibadan,

Ibadan, Nigeria

ooakinyemi@comui.edu.ng;

seunakinyemi@hotmail.com

Tel: +2348035020136

\begin{abstract}
Objective: To determine if primary school pupils aged 9-14 years can be satisfactorily trained, using the child-to- parent approach, to assess vision, refer and motivate people to attend screening eye camps.

Methods: Ninety pupils aged 9-14 years attending two purposively-selected primary schools were selected by simple random sampling. Using the child-to-parent approach and Snellens 6/60 illiterate E-chart, participants had a three-day knowledge and skill-based training followed by 2 days of community-based vision assessment and referral of those assessed. The adequacy and success of the training were assessed by comparing preand post-test scores.

Results: Three hundred and thirty-six persons were referred and examined; of these, $142(42.3 \%)$ persons were reviewed. Overall, there was significant improvement in knowledge. The accuracy of assessments was $82.1 \%$ for Right Eyes (RE), 83.3\% for Left Eyes (LE) and 72.1\% for presbyopia. The sensitivities for the RE, LE and presbyopia were $84.8 \%, 86.1 \%$ and $76.3 \%$ respectively. Similarly, the specificities were $44.4 \%$ for RE, $\mathbf{5 0 . 0} \%$ for $\mathrm{LE}$ and $68.6 \%$ for presbyopia. The performances were not significantly influenced by age, sex and locality.

Conclusion: Children aged 9-14 years in primary schools can be empowered, using the child-to-child approach, to assess vision and motivate members of their communities to utilize available eye care services.
\end{abstract}

\section{INTRODUCTION}

The global estimates for visual impairment and blindness in all ages, are currently 285 million and 39 million respectively; ${ }^{1}$ yet, $75-80 \%$ of blindness is preventable. ${ }^{1}$ About $80 \%$ of all visually impaired persons and $70 \%$ of all blind individuals are fifty years and above. Moreover, with the global economic growth, increased health awareness and life expectancy, populations are ageing and non-communicable diseases are attaining greater significance in eye care. Intensified efforts will therefore be needed to eliminate avoidable blindness and visual impairment. ${ }^{2}$

Despite the challenges of poor vision and the proven benefits of service utilization, a substantial number of affected individuals do not access available services even when provided as outreaches with partial or full sponsorship. ${ }^{3}$ The observed poor uptake of eye care service could be 'provider' or 'consumer' related. A lot of social marketing is thus currently being done by providers to ensure provision of good quality service to consumers and better uptake by users. ${ }^{3,4}$

The novel strategy of empowering children to share in the responsibility for improving their health and that of their communities using the child-to-child or childto-parent approach has been successfully implemented in other health areas and may have a place in eye care. ${ }^{5}$ Over 95 countries including India, Zambia, Botswana, Uganda, Jamaica and Madagascar have conducted child-to-child projects which targeted various health and development issues peculiar to their communities and these were successful; success was measured by various levels of desired change. However of the many projects, the few that have been evaluated did not discuss their outcomes in relation to age, sex, or community settings of children involved. ${ }^{6,7}$ Additionally, available evidence are in support of using this approach to promote eye health and prevent blindness in developing economies. 8,9 
In Nigeria children are an integral part of households and communities. From an early age, they assume responsibilities of caring for younger siblings and physically/mentally challenged relatives, watching over wares, and occasionally street hawking. Strong social ties and respect are known to exist between families living in communities. Children aged 5-14 years are $24.4 \%$ of the Nigerian population; there are 14,917,987 and 666,719 primary school pupils nationwide and in Oyo-State respectively. ${ }^{10}$ If they are involved in improving eye health, by the time they mature into adults, their health (including eye) awareness and practice will be better than those of their parents; ${ }^{11}$ they will have a better orientation to education and self-esteem. ${ }^{12}$ Furthermore, the prevalence of blindness among individuals $\geq 40$ years in the Southwest geopolitical zone is $2.8 \%$ (Presenting Visual Acuity). ${ }^{13}$ This translates into 150,930 individuals, being the lowest among the six geopolitical zones in the country. ${ }^{13}$ However, the zone has the highest number of health (and eye) care workers in the country. ${ }^{14}$

Although information on use of child-to-child approach in Nigeria is scarce, it has been recommended for eye health and child care by some local publications. 15, 16 Thus, this study was conducted to determine if primary school pupils aged 9-14 years could be satisfactorily involved in identifying and motivating visually impaired members of their communities to utilize available eye care services in rural Oyo State, Southwest Nigeria.

\section{METHODOLOGY}

\section{Study area}

Oyo state is located in the Southwest geopolitical zone of Nigeria, and is the largest of the six states in the zone with respect to size. The capital city is Ibadan, the largest in black Africa, ${ }^{10}$ with a population of about 5.58 million people who are mainly Yorubas, and farmers. Oyo state has 17 practicing ophthalmologists and all are located in Ibadan. Several optometry clinics providing primary eye care and optical services are located all over the state. In addition to these, several regular eye outreach services are provided by both public and mission hospitals to underserved areas of the state.

\section{Study sites}

The study was conducted at St. Paul's School, Latunde (School A) and CRIN Staff School 1, Idi Ayunre (School B) in Oluyole Local Government Area (LGA) of Oyo State, Southwest Nigeria between June and July 2012. Latunde is rural and located $60 \mathrm{~km}$ from the University College Hospital (UCH), Ibadan. It has a population of 7000 people, a Primary Health Centre (PHC) and a private clinic which offers primary health care but no eye care, and School A with total enrolment of 130 pupils (2012) is the only primary school.

Idi Ayunre (the LGA headquarters) is semi urban and located $20 \mathrm{~km}$ from UCH. It has 12,000 people, two PHCs and one General Hospital (the only one in the LGA), no eye care service, and three big primary schools one of which is School B with total enrolment of 506 pupils.

\section{Study design}

This pilot study followed an evaluation of intervention design. Ninety pupils were selected by simple random sampling through balloting from two purposively identified schools ${ }^{17}$.

\section{Sampling method}

The schools were purposively selected based on the setting (rural and semi urban-to allow for comparison), and accessibility. In each school, a list of all children aged 9-14 years and in classes 4-6 was compiled from the attendance register. Pupils who met the selection criteria but who had visual, hearing or mental disability were excluded (as the field team were not equipped to adequately train these categories of pupils). Similarly, pupils who could not read and write English or Yoruba were excluded.

Based on the population of pupils in each school, the sample size of 90 was proportionately allocated between Schools A and B at a ratio 1:2. At School A, the required sample of 30 pupils was satisfied by selecting all the pupils in these three classes (16 males and 14 females). At School B using the compiled list, the pupils were stratified by sex and class. Using a systematic random sampling, 60 pupils (31 males and 29 females) were selected in the same sex and class ratios as the sample obtained at School A. Parents of four pupils (two boys and two girls) did not consent to them participating, so they were replaced using the same sampling technique.

Furthermore, all the 3 teachers at School A were selected while at School B, 7 teachers (out of 17) were selected by simple random sampling. They gave their verbal consent to complete questionnaires commenting on the study approach at the end of the study. Members of the field work team consisted of two each of the following specialists; ophthalmologists, public health nurses, research assistants and clinic assistants.

\section{Using the child-to-parent approach}

The study was conducted at School A (week 1), School B (week 2) and both schools (week 3). The stages were the same in both schools - selection of participants, 
pre-test, training and post-test. The training team comprised of 2 ophtalmologists, 2 public health nurses, 2 clinic assistants and 2 research assistants. In each school, participants were trained over a three-day period. The goal of the training was to teach pupils the causes and challenges of poor vision as well as to empower them to help persons who suffer from this condition. Figures 1-3 shows pictures from the training sessions.

\section{Data analysis}

All quantitative data were entered into MS Excel spread sheet, coded if not numerical, and then cleaned. The data were transferred and analysed using STATA 12. New variables were generated to pull together all assessments (pupils and ophthalmologists separately) of VA (RE), VA (LE) and Presbyopia, and identify the eyes/persons correctly assessed (taking the ophthalmologist as the standard). Descriptive statistics such as means were used to summarize quantitative variables while categorical variables were summarized using percentages. Chi square test was used as test of significance of associations between categorical variables, one way test to compare means within and between categorical variables and t-test (paired and unpaired) to compare means. Statistical significance was considered at 95\% confidence level.

Qualitative data were extracted from the questionnaires and grouped into coded themes and entered into the Excel spread sheet. Coded themes for qualitative data were tabulated and results extracted in percentages. The raw data for this study may be accessed through: https://drive.google.com/file/d/0BxDImGBDiH1RkttVFJkbjh1M2M/view .
The London School of Hygiene and Tropical Medicine Research Ethics Committee (No: 011/415) and the University of Ibadan/University College Hospital Ethics Committee (NHREC/05/01/2008a) provided ethical clearance for this study. Furthermore, a threetiered permission was taken before involving the pupils. A written permission from Oluyole Local Government Area education secretary was obtained and parents and teachers were adequately informed about the study during Parent Teachers' Association (PTA) meetings that were held the week preceding the study in each school. The same day, informed consent forms were sent to parents of selected pupils through their children and these were returned by the end of the same week. Also, assent forms were completed by the selected pupils to indicate their willingness to participate. Likewise, written consent was taken before referred individual were reviewed; parents gave consent on behalf of their children. All consent forms were administered in English language and Yoruba, the local language.

\section{RESULTS}

\section{Socio-demographic characteristics of participating pupils}

Ninety pupils aged 9-14 years participated in this study. None of the pupils was on spectacle correction. The mean ages in schools $\mathrm{A}$ and $\mathrm{B}$ were $11.7 \pm 1.3$ years and $11.1 \pm 1.4$ years respectively. Table 1 summarises the socio-demographic characteristics of participants.

\section{Performance in pre-test and post-test}

Overall, mean post-test score was significantly higher than pre-test scores $(\mathrm{p}<0.0001)$. Significant improvement was also seen when considered by

Table 1: Socio-demographic characteristics of participating pupils

\begin{tabular}{lcccccc}
\hline & \multicolumn{2}{c}{ School A } & \multicolumn{2}{c}{ School B } & Total & \\
& $\mathbf{n}$ & $\mathbf{\%}$ & $\mathbf{n}$ & $\mathbf{\%}$ & $\mathbf{( N )}$ & $\mathbf{\%}$ \\
\hline Age group (years) & & & & & & \\
9-11 & 11 & 24.4 & 34 & 75.6 & 45 & 50.0 \\
12-14 & 19 & 42.4 & 26 & 57.8 & 45 & 50.0 \\
Sex & & & & & & \\
Male & 16 & 53.3 & 31 & 51.7 & 47 & 52.2 \\
Female & 14 & 46.7 & 29 & 48.3 & 43 & 47.8 \\
Class & & & & & & \\
4 & 9 & 30 & 19 & 31.7 & 28 & 31.1 \\
5 & 12 & 40 & 21 & 35 & 33 & 36.7 \\
6 & 9 & 30 & 20 & 33.3 & 29 & 32.2 \\
Total & $\mathbf{3 0}$ & $\mathbf{3 3 . 3}$ & $\mathbf{6 0}$ & $\mathbf{6 6 . 7}$ & $\mathbf{9 0}$ & $\mathbf{1 0 0}$ \\
\hline
\end{tabular}


Table 2: Comparing pre- and post- test scores* between groups

\begin{tabular}{llll}
\hline & $\begin{array}{l}\text { Mean Pre-test Score } \\
\text { (95\% Confidence } \\
\text { Interval) }\end{array}$ & $\begin{array}{l}\text { Mean Post-test Score } \\
\mathbf{9 5 \%} \text { Confidence } \\
\text { Interval) }\end{array}$ & $\begin{array}{l}\text { Difference between } \\
\text { post- and pre-test } \\
\text { scores (95\% } \\
\text { Confidence Interval) }\end{array}$ \\
\hline $\begin{array}{l}\text { Overall } \\
\text { Locality (School) }\end{array}$ & $3.2(2.9-3.5)$ & $4.5(4.3-4.8)$ & $1.3(1.0-1.7)$ \\
School A & $3.0(2.3-3.6)$ & $4.9(4.6-5.2)$ & $1.9(1.4-2.4)$ \\
School B & $3.3(2.9-3.7)$ & $4.4(4.0-4.7)$ & $1.1(0.7-1.5)$ \\
Sex & & & $1.5(1.1-1.9)$ \\
Male & $3.1(2.6-3.5)$ & $4.6(4.3-4.9)$ & $1.1(0.6--1.7)$ \\
Female & $3.3(2.9-3.8)$ & $4.5(4.0-4.9)$ & $1.3(-0.4-3.0)$ \\
Age group (years) & & & $1.4 \pm 1.4(0-2.8)$ \\
9-11 & $3.0(1.5-4.5)$ & $4.3(2.7-5.9)$ & \\
$12-14$ & $3.4(2.0-4.8)$ & $4.7(3.7-5.7)$ & \\
\hline
\end{tabular}

*Maximum score for both the pre- and post-tests is 7

locality (school) and sex. See Table 2 for details. School A had a higher post-test score compared to School B. School A is also the more improved school $(\mathrm{p}<0.0001)$. Similarly, males scored higher in the post-test; compared to females, males were more improved $(\mathrm{p}<0.0001)$.

Number of persons referred and reviewed, by pupils' age, sex and locality

Per age group, the number of persons referred exceeded that reviewed (Figure 4). The differences between the ages, in numbers referred and reviewed, were not statistically significant at $95 \%$ confidence level, $\mathrm{p}=0.45$ and 0.80 respectively.

Table 3: Socio-demographic characteristics of persons reviewed $(\mathrm{N}=142)$

\begin{tabular}{lll}
\hline & No. (n) & \% of Total \\
\hline Age group (years) & & \\
$0-20$ & 7 & 4.9 \\
$21-40$ & 26 & 18.3 \\
$40-60$ & 66 & 46.8 \\
$>60$ & 43 & 30.3 \\
Sex & & \\
Male & 50 & 35.2 \\
Female & 92 & 64.8 \\
Level of Education & & \\
None & 43 & 30.3 \\
Primary & 51 & 35.9 \\
Secondary & 31 & 21.8 \\
Post-Secondary & 17 & 12 \\
Occupation & & \\
Traders \& farmers & 89 & 62.7 \\
Civil servants & 33 & 23.2 \\
Artisans & 11 & 7.8 \\
Students & 9 & 6.3 \\
\hline
\end{tabular}

Figure 5 shows that females referred more persons but males had more persons reviewed. The differences between both sexes in numbers referred and reviewed were -0.25 ( -1.0 to 0.5$), \mathrm{p}=0.54$ and $0.39(-0.27$ to $1.04), p=0.24$ respectively, which were not statistically significant.

A higher number of persons were referred to and reviewed at School A (rural setting). The differences in these numbers between School A and School B, 0.6 $(-0.2$ to 1.4$), \mathrm{p}=0.16$ and $0.48(-0.2$ to 1.1$), \mathrm{p}=0.15$, for referred and reviewed persons respectively were not statistically significant. See Figure 6.

Table 4: Visual acuity $(<6 / 60)$ distribution of reviewed persons by age

\begin{tabular}{lll}
\hline $\begin{array}{l}\text { Age group } \\
\text { (years) }\end{array}$ & $\begin{array}{l}\text { No. with VA<6/60 } \\
\text { Both eyes (BE) }\end{array}$ & $\begin{array}{l}\text { \% SVI / } \\
\text { Blind }\end{array}$ \\
\hline $0-20$ & 0 & 0 \\
$21-40$ & 1 & 3.8 \\
$40-60$ & 4 & 6.1 \\
$>60$ & 5 & 11.6 \\
\hline
\end{tabular}

Table 5: Analysis of VA and presbyopia assessment done by pupils

\begin{tabular}{lccc}
\hline & $\begin{array}{c}\text { VA RE } \\
\mathbf{( \% )} \\
\mathbf{N = 1 3 3}\end{array}$ & $\begin{array}{c}\text { VA LE } \\
\mathbf{( \% )} \\
\mathbf{N = 1 3 2}\end{array}$ & $\begin{array}{c}\text { PRESBYOPIA } \\
\mathbf{( \% )} \\
\mathbf{N = 1 2 9}\end{array}$ \\
\hline Sensitivity & 84.8 & 86.1 & 76.3 \\
Specificity & 44.4 & 50.0 & 68.6 \\
Accuracy & 82.1 & 83.3 & 72.1 \\
\hline
\end{tabular}


Table 6: Comments of teachers and pupils about the study

\begin{tabular}{lll}
\hline Comment & Teachers (10) & Pupils (30) \\
$\begin{array}{l}\text { Experience with children } \\
\text { participating }\end{array}$ & $\begin{array}{l}\text { Impressive performance (100\%). } \\
\text { "It has empowered the children to be } \\
\text { achievers" (60\%) }\end{array}$ & $\begin{array}{l}\text { Happy and good 26 (86.7\%); } \\
\text { satisfied 4 (13.3\%) }\end{array}$ \\
$\begin{array}{l}\text { Teaching and training } \\
\text { during the study }\end{array}$ & $\begin{array}{l}\text { Good, simple and friendly (100\%) } \\
\text { Effect of study on the } \\
\text { community }\end{array}$ & $\begin{array}{l}\text { Good, simple and friendly } \\
(100 \%)\end{array}$ \\
$\begin{array}{l}\text { Positive (100\%). It will raise } \\
\text { awareness, reduce eye diseases and } \\
\text { need to go to the hospital in the } \\
\text { community (60\%) }\end{array}$ & $\begin{array}{l}\text { It will help people with eye } \\
\text { problems (70\%); "It will let } \\
\text { people know about eye disease } \\
\text { and what to do" (30\%) }\end{array}$ \\
$\begin{array}{l}\text { Will allow their children/wards to } \\
\text { programmes }\end{array}$ & $\begin{array}{l}\text { They will all participate; "I want } \\
\text { to help my community" }\end{array}$ \\
& $\begin{array}{l}\text { community to develop and "empower } \\
\text { the children to be doctors in future" }\end{array}$ & \\
\hline
\end{tabular}

Socio-demographic characteristics of the reviewed persons

From Table 3, the 40-60 year group had the highest attendance $(46.8 \%)$ followed by the $>60$ year group $(30.3 \%) ; 50$ were males $(35.2 \%)$ and 92 females $(64.8 \%)$. About two-thirds $(66.2 \%)$ of the reviewed persons had either primary or no education. Similarly,

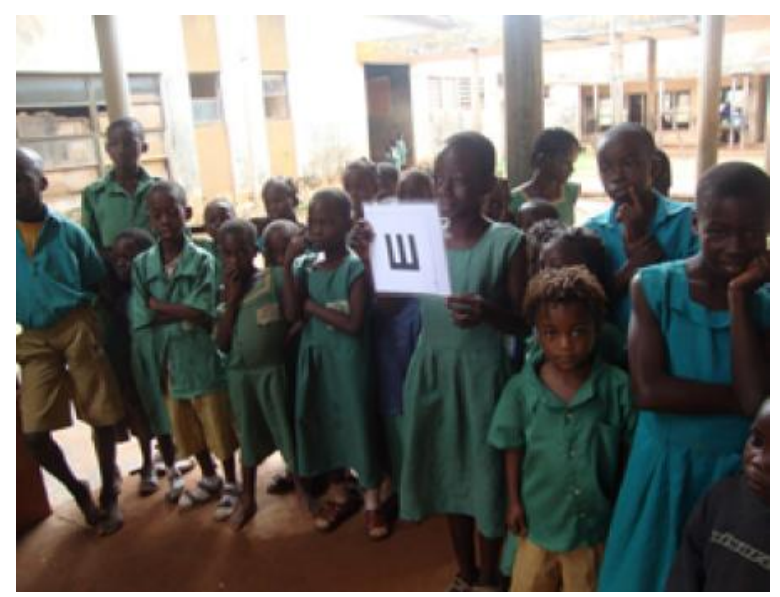

Fig. 1: A pupil assessing her colleague's vision during the skill training

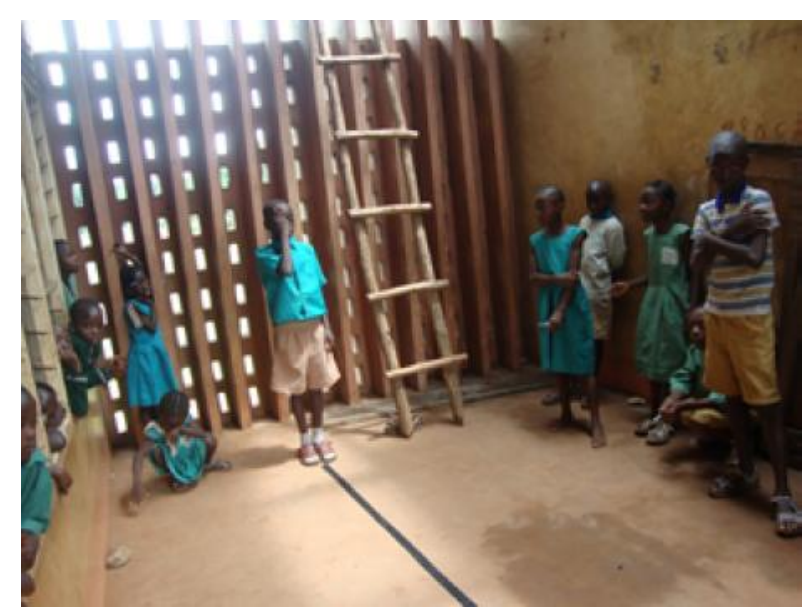

Fig. 2: The colleague undergoing the assessment traders and farmers were $62.7 \%$ of those reviewed while civil servants were $23.2 \%$, artisans (bricklayers, carpenters, plumbers and welders) were $7.8 \%$ and students (primary, secondary and tertiary) were 6.3\%. Percentage with SVI/ blindness increased with age and was $6.3 \%$ of persons reviewed (Table 4). More than $40 \%$ of the persons reviewed were pupils' neighbours.

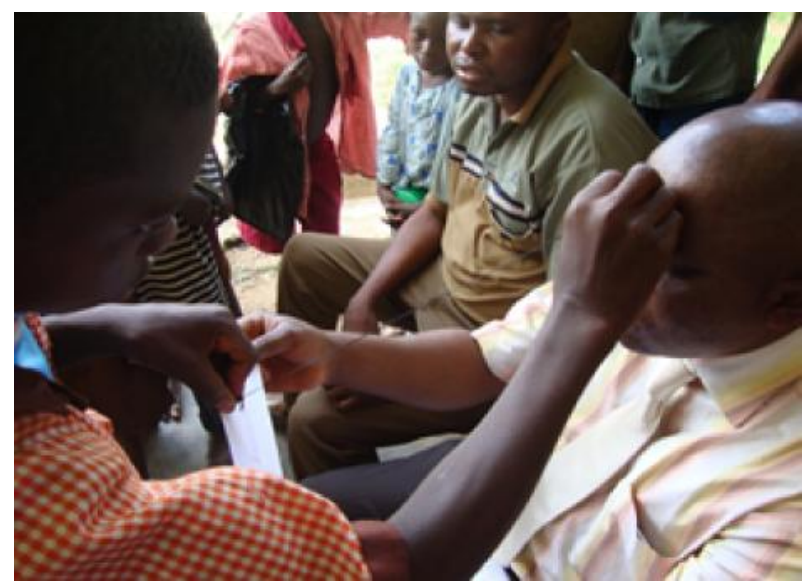

Fig. 3: A pupil demonstrating presbyopia assessment on a field team member

The pupils also succeeded in bringing some of their parents $(25.3 \%)$ and grandparents $(19.7 \%)$ as well as other relations

Review of vision assessments made by pupils Assessment of VA and presbyopia (the ophthalmologist as standard)

Assessments for 133 (RE) and 132 (LE) were documented by the pupils. The sensitivity, specificity and accuracy of the pupils' assessments are as detailed in Table 6. A total of 110 (RE and LE) and 93 presbyopic assessments were made correctly. Assessment of vision in people with VA $\geq 6 / 60$ was 


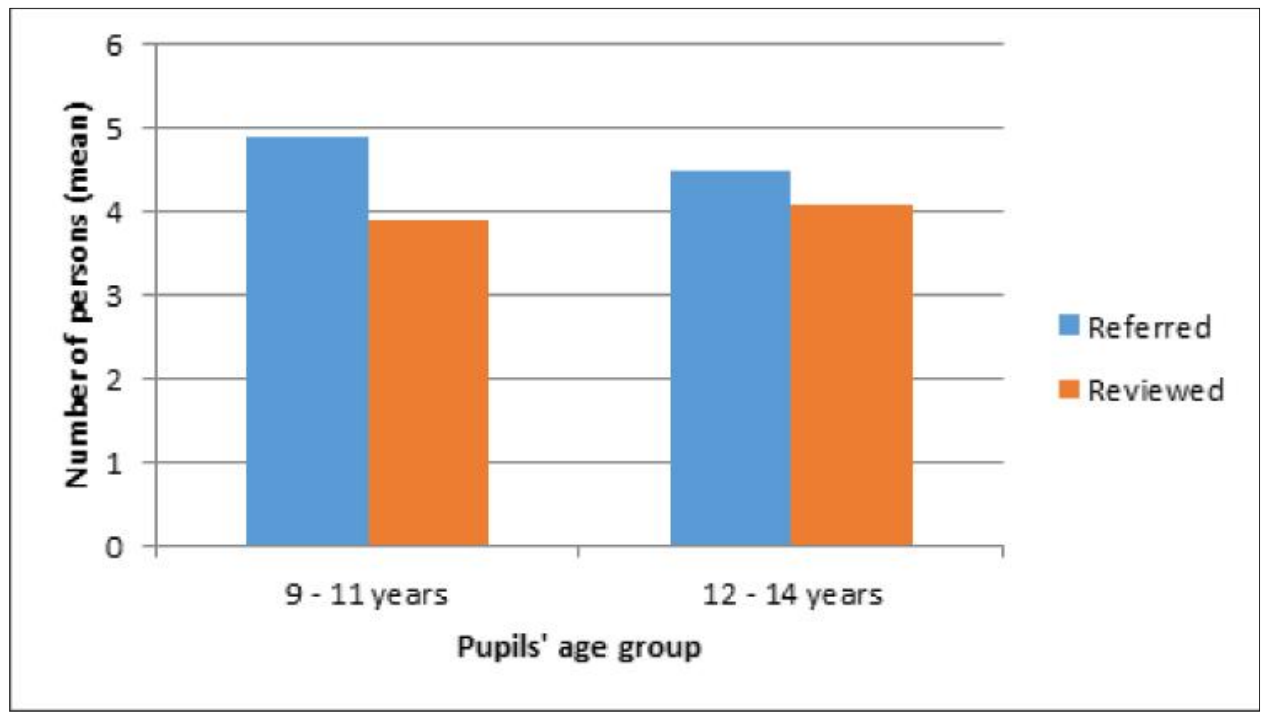

Fig. 4: Number of persons (mean) referred and reviewed, by pupils' age group

very accurate but less accurate in those with $\mathrm{VA}<6 /$ 60. The reverse applied in presbyopia where the assessment was more accurate in those with presbyopia and less accurate in those without. Overall, the accuracy of their assessments was high.

For VA assessment, younger persons were more likely to be correctly assessed, mean age being $51.0 \pm 3.0$ years compared to $56.0 \pm 5.0$ years for incorrect assessments; this relationship was not statistically significant $[\mathrm{p}=0.12(\mathrm{RE}), 0.22(\mathrm{LE})]$.

For presbyopia assessment, older persons were more likely to be correctly assessed, mean age being 54.4 (51.1-57.3) years, compared to 48.5 (42.8-54.1) years for incorrect assessment; this relationship was not statistically significant at $95 \%$ confidence level, $\mathrm{p}=0.06$.
Association between occupations, relationship to the pupil, educational attainment and being correctly assessed were not statistically significant at 95\% confidence level (these data are not shown in table).

Impressions of the reviewed persons, teachers and pupils about the child-to-child approach

Majority of the reviewed persons (79.3\%) agreed that the child-to-parent approach was good as it encourages uptake of eye care services by the blind and the visually impaired. All the reviewed persons also agreed that the approach will foster the development of the pupils and that of the community. Table 6 further highlights the frequency of agreements to some questions by the teachers and the pupils about the child-to-child approach.

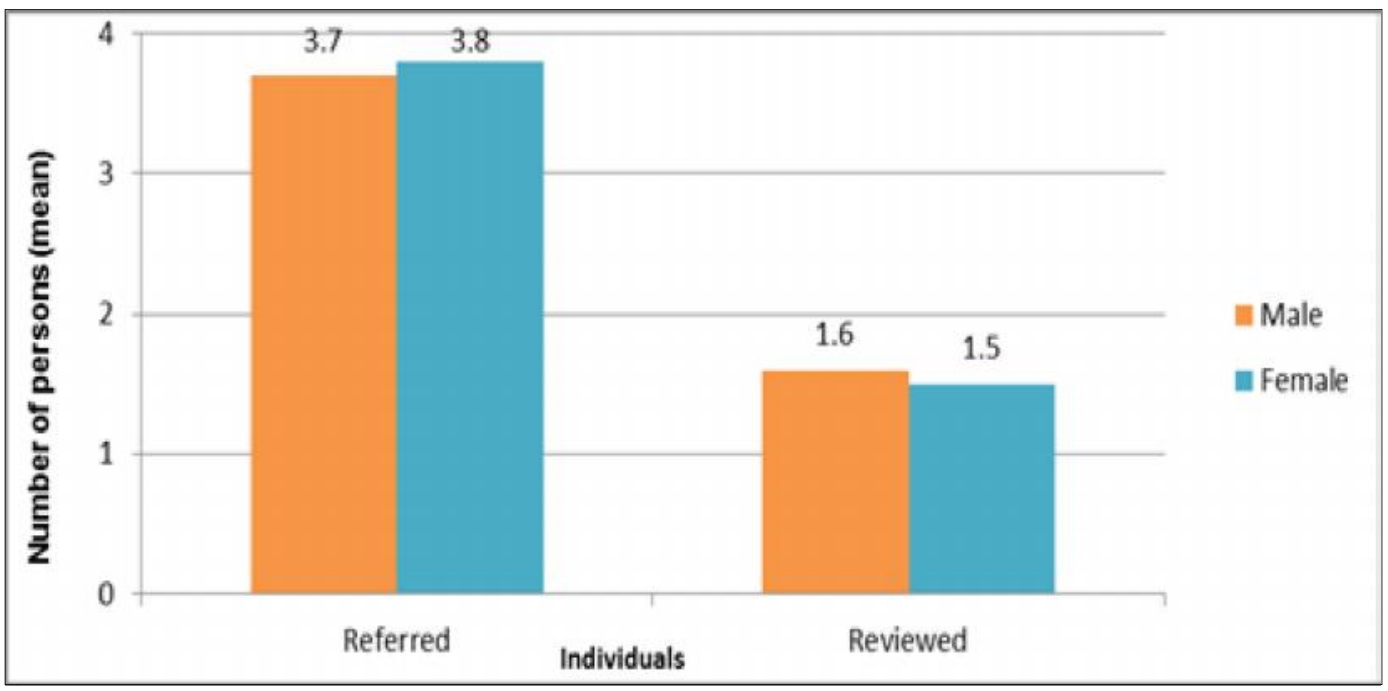

Fig. 5: Number of persons referred and reviewed, by pupils'sex 


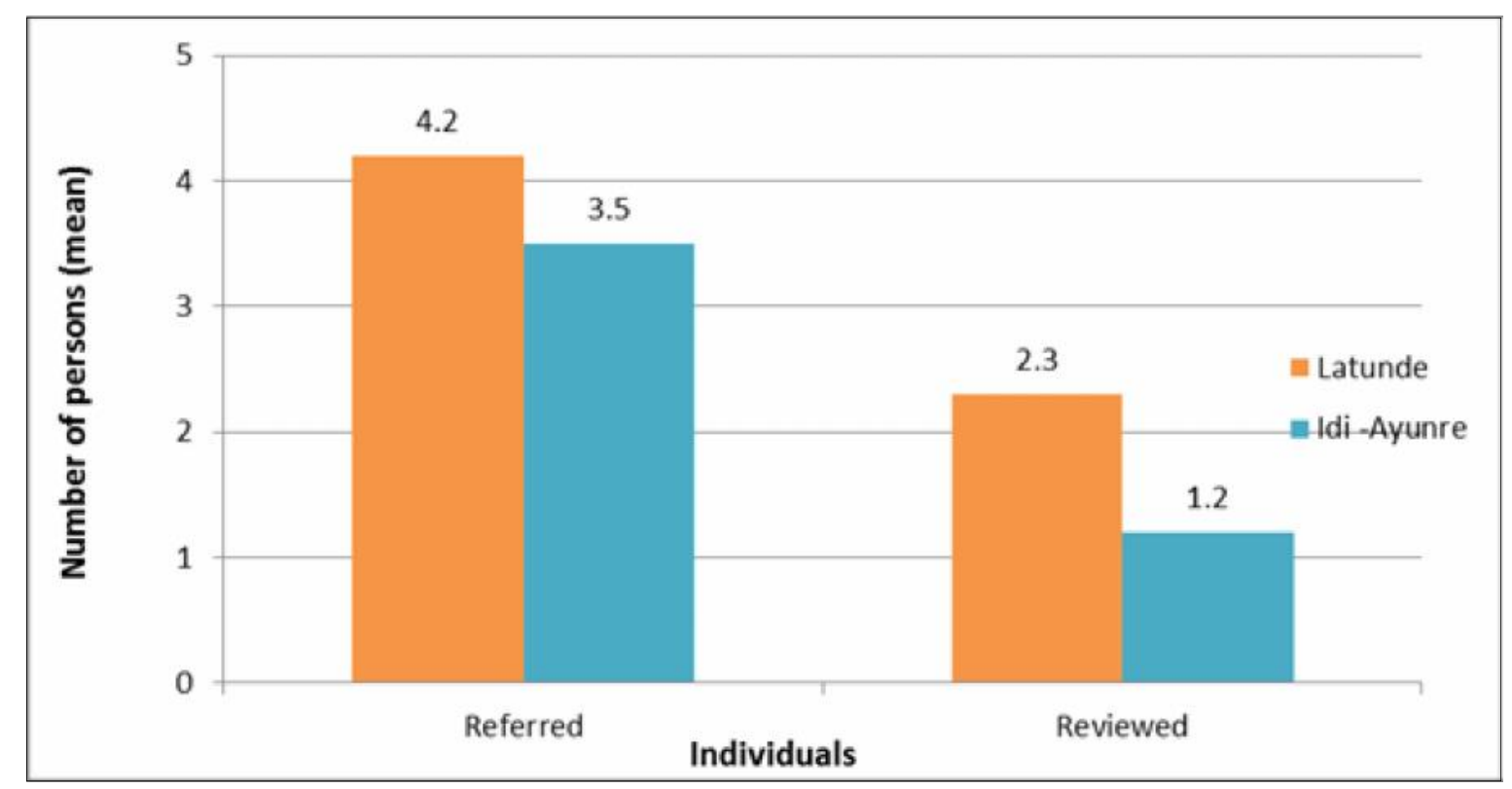

Fig. 6: Number of persons referred and reviewed by location of school

Participants' suggestions on improving on the child-to-parent approach

Half $(50.0 \%)$ of the teachers were of the opinion that having a longer and regular training for the children will have lasting impact on the community. Similarly, about a quarter $(24.3 \%)$ of the pupils suggested involving more children for them to really impact the community.

\section{DISCUSSION}

Child-to-parent approach trains children to identify important health issues in their communities, gather sufficient information about these, propose and take actions to effect change. ${ }^{12,18}$ This study already identified poor identification and uptake of eye care services by severe visually impaired and blind individuals as the problem so children were trained as agents to improve identification and uptake.

Children 9-14 years old in primary classes 4-6 were selected because they would be mature enough to understand the training and conveniently perform the expected tasks without exposure to most of the risks to adolescents in communities. Most studies concerning children have involved these ages. ${ }^{18,19}$ The child-tochild approach is effective in improving children's knowledge of poor vision using interactive health education technique which is characteristic of the method. Significantly higher mean post test scores were obtained across board and in each stratum except among the 9-year olds where the improvement was less appreciable. This was probably because they were the youngest group, the teaching technique was unfamiliar to them and they require time to adapt. However, studies done in the United Kingdom and Pakistan involved even younger children with success ${ }^{19}$, ${ }^{20} \mathrm{Mahr}$ in Madagascar and Onyango in Kenya also found health education improved knowledge of health topics among children. ${ }^{18,21}$ Evidence from child-tochild project in India where children were trained as "little doctors" for control of scabies and common skin infections also confirm tasks were clearly understood because skin infections reduced. ${ }^{12}$

A Snellens illiterate 'E' 6/60 optotype chart was used to assess VA because it is easy to use; the ultimate goal is to train the children to reliably identify severe visually impaired and blind individuals. In some settings children are taught to count fingers at $6 \mathrm{~m}$ instead; $; 22,23$ however, using Snellens' optotype is more objective as it allows for comparison and ensures quality provided each rotation of the optotype is done out of view before being presented to the subject. VA was assessed for each eye and not the individual to ensure the pupils were comfortable with assessing and documenting distance vision. The interpretation and documentation of findings was also simplified to terms they were familiar with: "yes" or "no".

Presbyopia was assessed using N8 optotype at $40 \mathrm{~cm}$ because this is equivalent to newspaper print at $40 \mathrm{~cm} ; 24$, 25 at this distance most near work is done. Only persons 30 years and above were assessed; $30-40$ year range was considered because presbyopia sets in earlier in blacks, and being rural/ semi-rural communities where documentation of birth is poor the people may be older than ages estimated for them. The beaded 
twine used made the procedure attractive, interesting and helped ensure the $40 \mathrm{~cm}$ working distance was kept. The performance at vision assessment was very good and accurate; also, normal vision and presbyopic patients were better assessed. Probably because of the short training, and presbyopia assessment being easier to make in this study, presbyopia assessment improved with increase in number of persons assessed but VA assessment did not. With continued practice and evaluation of results, the children should improve in assessing the visually impaired and blind too.

Although all the ages performed satisfactorily, the performance of 12 and 13year olds respectively in the post test and the number of persons referred and reviewed were the highest, and that of 9year olds the lowest. Their good background knowledge of poor vision, academic maturity and experiences living in the communities could have enhanced their performance. Being older, they might be more outgoing and matured in applying the knowledge and skills acquired thereby earning community confidence and having better results.

The confidence intervals for the post test scores show that knowledge of health education of both sexes is equally good. Regarding number of referred and the perception of all interviewed participants about the approach was good. They foresee the approach developing their community and empowering their children, if it is improved to ensure the children are properly trained. This was probably why they turned out in large numbers and will allow their children to participate in similar programmes in future. A good community perception indicates acceptance and support; this should be encouraged.

However, some limitations of this study should be highlighted. The sample size was not statistically representative because this was a pilot study; minimal variations between groups may be evident with larger sample size. The small sample size may thus limit the genaralisability and reliability of the findings of this study. Also, the presbyopic assessments done did not initially correct for distance error which could have indicated the need to modify corrections given for near. Furthermore, those referred but not reviewed may be different from those who were reviewed; having their socio-demographic data and contact would have been helpful in finding out their reasons for not keeping the appointments which will be useful for future planning. Besides, without having undertaken a population-based examination of visual acuity, there was no idea of the false negative results that this studentbased screen might have encountered. Nevertheless, this study provides important preliminary data on the effectiveness of the child-to-child approach in a developing country like Nigeria.

\section{CONCLUSION}

Poor identification and utilization of available eye care services by visually impaired and blind persons is a problem in Ibadan, Nigeria as it is in most low income settings. This study found child-to-child approach to be simple, friendly and effective in improving children's knowledge and attitude toward visual impairment and blindness. This empowers children to go into their households and communities to reliably assess people's vision and motivate a sizeable number to attend reviews on appointment. Eye care programmes should adopt child-to-child approach, in addition to other strategies already in operation, to improve the identification and uptake of services by severe visually impaired and the blind in the rural, unreached communities.

\section{REFERENCES}

1. Pascolini D and Mariotti SP. Global estimates of visual impairment: 2010. Br J Ophthalmol. 2011.

2. Sherwin JC, Keeffe JE, Kuper H, et al. Functional presbyopia in a rural Kenyan population: the unmet presbyopic need. Clin Experiment Ophthalmol. 2008; 36: 245-251.

3. Bekibele CO, Murthy G.V.S. Cataract services uptake by outreach camp patients at Ibadan Nigeria. Deutsche Nationalbibliothek, Germany: LAP LAMBERT Academic Publishing Gmbh \& Co. KG 2012, 60.

4. Zhang M, Wu J, Li L, et al. Impact of cataract screening outreach in rural China. Invest Ophthalmol $V$ is Sci. 2010; 51: 110-114.

5. Hawes $\mathbf{H}$ and Scotchmer C. Children for Health. ERIC, 1993.

6. Ward D, Etya'ale D, Sil AK, et al. Outreach: linking people with eye-care. Community Eye Health. 2006; 19: 1-3.

7. Onyango-Ouma W, Aagaard-Hansen $J$ and Jensen B. The potential of school childrens health change agents in rural western Kenya. Soc Sci Med. 2005; 61:1711-1722.

8. Hubley $\mathbf{J}$ and Gilbert C. Eye health promotion and the prevention of blindness in developing countries: critical issues. BrJ Ophthalmol. 2006; 90: 279-284.

9. Sifri Z, Bendech MA and Baker SK. School health programmes in Burkina Faso: the Helen Keller International experience. Food, Nutrition and Agriculture: Helen Keller Foundation. 2003; 33: 54-63. 
10. National Population Commission Nigeria. State population. 2012.

11. Serpell R, Mumba P and Chansa Kabali T. Early educational foundations for the development of civic responsibility: An African experience. New Dir Child Adolesc. 2011; 2011: 77-93.

12. Pridmore P, Stephens D and Stephens J. Children as partners for health: a critical review of the childto-child approach. Zed Books, 2000.

13. Kyari F, Gudlavalleti MVS, Sivsubramaniam S, et al. Prevalence of blindness and visual impairment in Nigeria: The national blindness and visual impairment survey. Invest Ophthalmol V is Sci.. 2009; 50: 2033-2039.

14. Rabiu MM, Kyari F, Ezelum C, et al. Review of the publications of the Nigeria national blindness survey: Methodology, prevalence, causes of blindness and visual impairment and outcome of cataract surgery. Ann Afr Med.. 2012; 11: 125.

15. Okafor FU and Agwubike EO. Visual acuity and motor performance correlates in basic education school children of Edo State, Nigeria. Eur J Psychol Educ Studies 2012; 4.

16. Akinware M. Site Visit: Child Care and Woman's Work in Rural Nigeria. Washington D.C.: World Bank, 1999.

17. Kotrlik JWKJW and Higgins CCHCC. Organizational Research: Determining appropriate sample size in survey research. Inf. Technol. Learn. Perform. J.. 2001; 19: 43.
18. Mahr J, Wuestefeld M, Haaf JT and Krawinkel MB. Nutrition education for illiterate children in southern Madagascar - addressing their needs, perceptions and capabilities. Public Health Nutr. 2005; 8: 366-372.

19. Ahmad K, Khan M, Qureshi M, et al. Perceptions of eye health in schools in Pakistan. BMC Ophthalmol. 2006; 6: 8.

20. Woods SE, Springett J, Porcellato L and Dugdill L. 'Stop it, it's bad for you and me': experiences of and views on passive smoking among primaryschool children in Liverpool. Health Educ Res.. 2005; 20: 645-655.

21. Wilkinson J. Children and participation: Research, monitoring and evaluation with children and young people'. Briefing Paper. 2000.

22. Francis $\mathbf{V}$ and Wiafe B. The healthy eyes activity book. London: International Centre for Eye Health. 1996.

23. Moulton L. Community based rehabilitation and prevention of blindness in south west Uganda. Community Eye Health. 1998; 11: 51.

24. Burke A, Patel I, Munoz B, et al. Prevalence of presbyopia in rural Tanzania: a population-based study. Invest Ophthalmol Vis Sci. 2005; 46: 5629.

25. Nirmalan PK, Krishnaiah S, Shamanna BR, et al. A population-based assessment of presbyopia in the state of Andhra Pradesh, south India: the Andhra Pradesh Eye Disease Study. Invest Ophthalmol Vis Sci. 2006; 47: 2324-2328.

This is an open access article licensed under the terms of the Creative Commons Attribution Non-Commercial License (<uri xlink:href="http:/ / creativecommons.org/ licenses/ by-nc/ 3.0/ ">http:/ / creativecommons.org/ licenses/ by-nc/ 3.0</ uri>) which permits unrestricted, non-commercial use, distribution and reproduction in any medium, provided the work is properly cited. 